\title{
Prevalence Study of Ocular Morbidity among Primary School Children in Delhi Area
}

\author{
Sridhara Reddy ${ }^{1}$, Gurunadh Satyanarayana Velamakanni², Shailesh Mogra ${ }^{3}$
}

\begin{abstract}
Aim: To estimate the prevalence of ocular morbidity among primary school children in Delhi area.

Materials and methods: This was a descriptive cross-sectional study. The study was conducted among primary school children of age group 5-12 years in Delhi area. A total of 1,100 school-going children were evaluated. After questionnaire administration, visual acuity, examination of anterior and posterior segment structures of the eyes of the children were carried out. For the statistical analysis, children were divided into three groups: group I (5-7 years), group II (8-10 years), and group III ( $<12$ years) based on age.

Results: A total of 1,100 school children ( 625 boys and 475 girls) participated in the study. A total of $282(25.6 \%)$ children had visual impairment and $315(28.6 \%)$ children had ocular morbidities. The common ocular morbidities identified were refractive error $25.6 \%$, color vision defective $0.9 \%$, convergence defect $1.8 \%$, and squint $0.2 \%$. The older age group (8-10 years) had a higher prevalence of refractive error, especially myopia, compared to the younger age group ( $5-7$ years) and group ( $<12$ years) $(p<0.001)$.

Conclusion: A high prevalence of ocular morbidity among school children of age group 8-10 years was observed. Refractive errors were the most common ocular disorders. This study emphasized that a simple school visual screening program is effective for the early detection of ocular problems.

Keywords: Ocular morbidity, Refractive error, School children, Squint.

Journal of Medical Academics (2020): 10.5005/jp-journals-10070-0048
\end{abstract}

\section{INTRODUCTION}

It is estimated by studies that globally people with visual impairment is 253 million, among which 217 million have moderate-to-severe visual impairment. Among 19 million children under the age of 15 years, visual impairment due to undetected or inadequately corrected refractive errors accounts for 12 million. ${ }^{1}$

A poor academic performance is seen in children having undetected ocular disorders and leads to severe ocular disability later in life. ${ }^{2}$ Visual screening program of children benefits by providing early and suitable preventive ophthalmic care to the target population. It is confirmed by several community-based studies that approximately $75 \%$ of all vision-related problems in children were first identified at a visual screening program. ${ }^{3}$

Generally, children are not aware of their ocular problems unless specifically examined. Children tend to adopt compensatory methods for adjusting to the poor vision by sitting near the blackboard, holding the books closer to their eyes, and squeezing the eyes. ${ }^{4,5}$ A statistical data on causes and prevalence of ocular morbidity in children are essential for offering preventive and curative services in children. ${ }^{6}$ These ocular morbidities can be prevented by early detection and treatment.

The significant data for the study of preventable blindness fall in the school children of age group (6-16 years) accounting for $25 \%$ population in developing countries. Schools provide the best platform for imparting health education to the children. This study was carried out with the objective of estimating the prevalence of ocular morbidity among primary school children.

\section{Materials and Methods}

This is a cross-sectional study conducted among primary school children in Delhi area. The study was conducted in full accord with
${ }^{1}$ Department of Ophthalmology, Air Force Central Medical Establishment, New Delhi, India

${ }^{2}$ Department of Ophthalmology, GSL Medical College, Rajahmundry, Andhra Pradesh, India

${ }^{3}$ Department of Ophthalmology, Military Hospital, Jodhpur, Rajasthan, India

Corresponding Author: Sridhara Reddy, Department of Ophthalmology, Air Force Central Medical Establishment, New Delhi, India, Phone: +91 8472982326, e-mail: shrusri13@gmail.com

How to cite this article: Reddy S, Velamakanni GS, Mogra S. Prevalence Study of Ocular Morbidity among Primary School Children in Delhi Area. J Med Acad 2020;3(2):43-45.

Source of support: Nil

Conflict of interest: None

the tenets of the Declaration of Helsinki after obtaining approval from the Institutional Ethics Committee. Children attending Air Force schools in the age group of 5-12 years were included for the evaluation. The school management committee was informed in prior and permission from parents was as taken. Consent forms and questionnaire were distributed to all the primary school children. The questionnaire included any voluntary disclosure of significant ophthalmological history by parents.

The survey was conducted by history taking from the children, teachers, and from voluntary disclosure by parents in consent form. Examination was carried out in clean, quiet, and well-lit rooms within the school campus. Assessment of both aided and unaided visual acuity (VA) was performed using Snellen's chart. A pinhole VA was tested for children with VA less than 6/9. Refractive error was diagnosed when a VA worse than $6 / 9$ improved on a pinhole 
test. As per WHO classification, visual impairment was defined as presenting VA worse than $6 / 9$ in the better eye and classified into mild $(6 / 12-6 / 18)$, moderate $(<6 / 18-6 / 60)$, and severe impairment $(<6 / 60-3 / 60){ }^{7}$ Blindness was defined as best-corrected VA worse than $3 / 60$ in the better eye. ${ }^{1,8,9} \mathrm{~A}$ dry retinoscopy and subjective refractive error correction were given to the children. Children were checked for ocular movements and convergence insufficiency using Royal Air Force ruler (RAF). A detailed anterior segment examination was performed using a torch light and a slit-lamp. Color vision was tested in broad daylight using 32 plates Ishihara charts. Visual axis alignment was checked using cover-uncover, alternate cover, and Hirschberg tests. Undilated fundus examination was performed using a direct ophthalmoscope. Children not improving to $6 / 6$ with a pinhole and needing further assessment and management were referred to a tertiary care center.

The data collected from children were divided into three groups: group I (5-7 years), group II (8-10 years), and group III ( $<12$ years), based on age for the analysis. The final data were analyzed using SPSS version 16.0 for windows (IBM SPSS, IBM Corp., Armonk, New York, USA).

\section{Results}

Sample size of the study was 1,100 with children in the age group of 5-12 years. Among these, 625 (56.8\%) were boys and 475 (43.1\%) were girls. In the study, 785 (71.3\%) children had normal ocular findings and ocular morbidity was seen among 315 (28.6\%) children.

The prevalence of ocular morbidities seen in the children is tabulated in Table 1 and depicted in Figure 1. The refractive errors were VA improved with a pinhole testing accounted for $282(25.6 \%)$ followed by convergence deficiency accounting for $20(1.8 \%)$ of ocular morbidity. Color vision defect was responsible for 10 (0.9\%)

Table 1: Prevalence of various ocular morbidities

\begin{tabular}{lcll}
\hline Ocular morbidity & Children $(n=1,100)$ & Percentage & p value \\
\hline Ocular morbidity & 315 & 28.6 & 0.286 \\
Refractive error & 282 & 25.6 & 0.256 \\
Color vision defective & 10 & 0.9 & 0.009 \\
Convergence defect & 20 & 1.8 & 0.018 \\
Squint & 03 & 0.2 & 0.002 \\
\hline
\end{tabular}

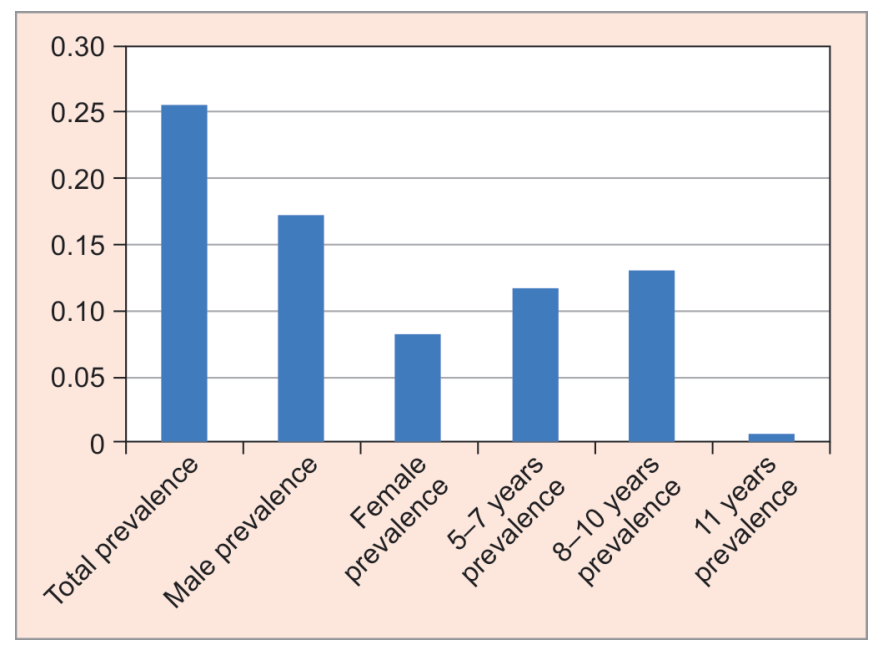

Fig. 1: Graph depicting the prevalence of ocular morbidities of ocular morbidities, and $3(0.27 \%)$ were due to squint with no cataract and glaucoma cases.

Seven hundred and eighty-five (71.3\%) children had normal vision while 282 (25.6\%) had impaired vision. Among the children with impaired vision, 199 (70.1\%) had mild, 60 (21.8\%) had moderate, and $23(8.0 \%)$ had severe impairment. Among refractive error, a total of $172(61 \%)$ children had myopia, 79 (28\%) astigmatism, and $3(11 \%)$ of hypermetropia seen in children. The ocular morbidity pattern was $34 \%$ in boys as compared to $21.4 \%$ in girls, which was statistically significant $(p<0.001)$ (Table 2$)$.

The analysis of ocular morbidity in the three age groups showed that group II (37.5\%) had a higher prevalence as compared to group I (19.8\%) and group III (29.6\%), but this difference was statistically insignificant ( $p=0.192$ ) (Table 3). The only factor that attained a statistically significant difference $(p<0.001)$ was refractive error. Myopia was noted to be higher in group II with 42 children (4.8\%) $(p=0.006)$.

\section{Discussion}

In our study, there were 625 boys and 475 girls. The prevalence of ocular morbidity was $28.6 \%$ with $34 \%$ in boys and $21.4 \%$ in girls. A varied prevalence reports is noted in previous studies based on data from different geographical areas and methodologies used. The Delhi-based study conducted by Kumar et al. ${ }^{7}$ reported a $22.7 \%$ prevalence. Gupta et al. ${ }^{3}$ in their study reported a $31.6 \%$ prevalence in Shimla. A study conducted by Chaturvedi and Aggarwal ${ }^{10}$ reported a $40 \%$ prevalence, which was due to higher prevalence of refractive error in their study. Shrestha et al. ${ }^{11}$ in their study in Kathmandu reported an overall prevalence of ocular morbidity as $34.2 \%$, which was comparable with our study.

The refractive error was found to be the most common cause of ocular morbidity with a prevalence of $25.6 \%$. These results were comparable with studies conducted by Gupta et al. ${ }^{3}$ who found refractive error as the most common disorder, with a prevalence of $22 \%$. International studies conducted by Shrestha et al. ${ }^{11}$ reported a similar prevalence of refractive error in their 2006 study (21.9\%)

Table 2: Prevalence of ocular morbidity based on gender

\begin{tabular}{lccc}
\hline & \multicolumn{2}{c}{ Gender } & \\
\cline { 2 - 3 } Ocular morbidity & Boys $(n=625)$ & Girls $(n=475)$ & p value \\
\hline Ocular morbidity & $213(34.0 \%)$ & $102(21.4 \%)$ & 0.286 \\
Refractive error & $190(30.4 \%)$ & $92(19.3 \%)$ & 0.256 \\
Color vision defective & $10(1.6 \%)$ & $0(0)$ & 0.009 \\
Convergence defect & $12(1.9 \%)$ & $8(1.6 \%)$ & 0.018 \\
Squint & $1(0.1 \%)$ & $2(0.4 \%)$ & 0.002 \\
\hline
\end{tabular}

Table 3: Various ocular morbidities based on age group

\begin{tabular}{|c|c|c|c|c|}
\hline \multirow[b]{2}{*}{ Ocular morbidity } & \multicolumn{3}{|c|}{ Age group } & \multirow[b]{2}{*}{$p$ value } \\
\hline & $\begin{array}{l}\text { Group I } \\
(n=344)\end{array}$ & $\begin{array}{l}\text { Group II } \\
(n=729)\end{array}$ & $\begin{array}{l}\text { Group III } \\
(n=27)\end{array}$ & \\
\hline Ocular morbidity & $135(42.8 \%)$ & $171(54.2 \%)$ & $9(2.8 \%)$ & 0.286 \\
\hline Refractive error & $129(37.5 \%)$ & 145 (19.8\%) & $8(29.6 \%)$ & 0.256 \\
\hline $\begin{array}{l}\text { Color vision } \\
\text { defective }\end{array}$ & $3(0.8 \%)$ & $7(0.9 \%)$ & 0 & 0.009 \\
\hline $\begin{array}{l}\text { Convergence } \\
\text { defect }\end{array}$ & $1(0.2 \%)$ & $2(0.2 \%)$ & 0 & 0.018 \\
\hline Squint & $2(0.5 \%)$ & $17(2.3 \%)$ & $1(3.7 \%)$ & 0.002 \\
\hline
\end{tabular}


and (11.9\%) in 2011 study in Nepal. Studies conducted by Das et al. ${ }^{12}$ in Kolkata and Desai et al. ${ }^{13}$ in Jodhpur also reported a similar prevalence of 25.11 and $20.8 \%$, respectively.

Lower prevalence of refractive errors (2.7-5.8\%) has been reported internationally among children of age 5 to 15 years from Africa, Finland, Chile, and Nepal as compared to the present study. ${ }^{14}$ These differences may be explained by the geographical variations in the prevalence of refractive errors, different lifestyles followed, medical care received, and different diagnostic criteria used in the studies.

The most common refractive error was myopia with a prevalence of $3.2 \%$ followed by astigmatism $1.4 \%$ and hypermetropia at $0.6 \%$. A similar prevalence of myopia (5.8\%) and hypermetropia $(0.7 \%)$ was reported by Aldebasi ${ }^{15}$ in their study. In a study conducted by Padhye et al., ${ }^{16}$ they reported a $4.61 \%$ prevalence of myopia, which was comparable with the present study; however, the prevalence of hypermetropia and astigmatism reported was 1.45 and $0.37 \%$, which was higher than the present study. The studies have shown that a higher prevalence of myopia is associated with an increase in literacy rate, the duration of study hours, and the age of the child. ${ }^{16}$

The difference in the prevalence of ocular morbidities among boys (34\%) and girls (21.4\%) was due to the higher prevalence of refractive error in boys (30.4\%) than girls (19.3\%). The prevalence of red-green color deficiency was found to be $1.6 \%$, which was comparable to results reported by Gupta et al. ${ }^{3}(2.3 \%)$ in their study. The frequency of color vision defects is higher among male children, which corroborate that genetically color vision is X-linked recessive nature.

In our study, the prevalence of convergence insufficiency was $1.8 \%$, which was comparable to a study conducted by Pratap and $\mathrm{Lal}^{17}$ who reported a prevalence of $1.72 \%$. The prevalence of squint was $0.27 \%$, which was similar and comparable to the prevalence reported in studies conducted by Desai et al. ${ }^{13}(0.21 \%)$. A higher prevalence of strabismus was reported by Shrestha et al. ${ }^{11}$ (3.5\%), Gupta et al. ${ }^{3}(2.5 \%)$, and Pratap and Lal ${ }^{17}(2.87 \%)$ in their studies.

The ocular morbidity was more in the group II (8-10 years) compared to group I (5-7 years) and group III ( $<12$ years), which was comparable with a study conducted by Kumar et al. ${ }^{7}$ Among older children, this could be attributed to the increase in awareness with age, which enables them to communicate their problems to the doctor in a better way which in turn leads to higher reporting of ocular problems.

\section{Conclusion}

Refractive error is the most common cause of treatable ocular morbidity according to our study. This study emphasized that a simple school visual screening program is effective for the early detection of ocular problems. Schools form a suitable platform where mass communication and awareness can be imparted. The early detection of color vision defects and counseling of parents and children guides them in choosing a suitable academic career.
Hence, there is a need for early evaluation and treatment of visual impairment before the vision and academic performance of children is affected. Limitations of the study include the smaller sample size of participants in group III ( $<12$ years).

\section{References}

1. Bourne RRA, Flaxman SR, Braithwaite T, et al. Magnitude, temporal trends, and projections of the global prevalence of blindness and distance and near vision impairment: a systematic review and metaanalysis. Lancet Glob Health 2017;5(9):e888-e897. DOI: 10.1016/ S2214-109X(17)30293-0.

2. Schmidt $P$, Maguire $M$, Dobson $V$, et al. Comparison of preschool vision screening tests as administered by licensed eye care professionals in the vision in preschoolers study. Ophthalmology 2004;111(4):637-650. DOI: 10.1016/j.ophtha.2004.01.022.

3. Gupta M, Gupta BP, Chauhan A, et al. Ocular morbidity prevalence among school children in Shimla, Himachal, North India. Indian J Ophthalmol 2009;57(2):133-138. DOI: 10.4103/0301-4738.45503.

4. Castanes MS. Major review: The underutilization of vision screening (for amblyopia, optical anomalies and strabismus) among preschool age children. Binocul Vis Strabismus Q 2003;18:217-232.

5. Vision screening in school children. Training module. Danish Assistance to the National Programme for Control of Blindness. New Delhi, India: 1.

6. Dandona R, Dandona L, Srinivas M, et al. Refractive error in children in a rural population in India. Invest Ophthalmol Vis Sci 2002;43: 615-622.

7. Kumar R, Dabas P, Mehra M, et al. Ocular morbidity amongst primary school children in Delhi. Health Popul Perspect Issues 2007;30: 222-229.

8. Resnikoff S, Pascolini D, Mariotti SP, et al. Global magnitude of visual impairment caused by uncorrected refractive errors in 2004. Bull World Health Organ 2008;86(1):63-70. DOI: 10.2471/BLT.07.041210.

9. Naidoo K, Govender P. Case finding in the clinic: refractive errors. Community Eye Health 2002;15:39-40.

10. Chaturvedi S, Aggarwal OP. Pattern and distribution of ocular morbidity in primary school children of rural Delhi. Asia Pac J Public Health 1999;11(1):30-33. DOI: 10.1177/101053959901100107.

11. Shrestha RK, Joshi MR, Ghising R, et al. Ocular morbidity among children studying in private schools of Kathmandu valley: a prospective cross sectional study. Nepal Med Coll J 2006;8:43-46.

12. Das $A$, Dutta $H$, Bhaduri $G$, et al. A study on refractive errors among school children in Kolkata. J Indian Med Assoc 2007;105:169-172.

13. Desai S, Desai R, Desai NC, et al. School eye health appraisal. Indian J Ophthalmol 1989;37:173-175.

14. Wedner SH, Ross DA, Balira R, et al. Prevalence of eye diseases in primary school children in a rural area of Tanzania. Br J Ophthalmol 2000;84(11):1291-1297. DOI: 10.1136/bjo.84.11.1291.

15. Aldebasi YH. Prevalence of correctable visual impairment in primary school children in Qassim Province, Saudi Arabia. J Optom 2014;7(3):168-176. DOI: 10.1016/j.optom.2014.02.001.

16. Padhye AS, Khandekar R, Dharmadhikari $S$, et al. Prevalence of uncorrected refractive error and other eye problems among urban and rural school children. Middle East Afr J Ophthalmol 2009;16(2): 69-74. DOI: 10.4103/0974-9233.53864.

17. Pratap VB, Lal HB. Pattern of paediatric ocular problems in North India. Indian J Ophthalmol 1989;37(4):171-172. 